\title{
Factors Governing Outsourcing Engineering Consultancy in Saudi Arabian Construction Industry
}

\author{
Badr Alsulami ${ }^{1}$, Usama Issa ${ }^{2}$, and Sherif Mohamed ${ }^{3}$
}

\begin{abstract}
Construction Projects in the Public Sector (CPPS) of the Kingdom of Saudi Arabia (KSA) represent large value investments. Further, the need for outsourcing engineering consultancy is becoming more and more critical for the provision of CPPS. In this paper, a total of 30 factors are identified and used in a field survey for the purpose of collecting data pertaining to the current level of outsourcing Engineering Consultancy in Construction Projects (ECCP) in the KSA. The local practices are explained, including those detailing consultants' responsibilities in CPPS, and selecting consultants based on the type of contract adopted. A detailed analysis is conducted, based on agreement tests (including the Spearman's test and the boxplot analysis) among the experienced partners who participated in the field survey. The importance of each identified factor is determined through a simple Relative Importance Index (RII); then the factors are grouped according to the type of contract (either supervision or design contract). The results highlighted that many factors are indirectly, and not officially, used in the consultants' evaluation after selection. The paper introduces a list of governing factors for outsourcing ECCP in the KSA with relative weights; these weights can be used by the owners in evaluating and selecting the consultants and the preparation of contracts with complete clarification of the consultants' responsibilities. The list can be used by the consultants in evaluating and developing their organization, as well as focusing on their core competencies in order to accomplish their business mission.
\end{abstract}

Keywords: Consultants selection, Saudi Arabia, Outsourcing.

\section{Introduction}

Outsourcing can be defined as the process by which a client employs a separate company, under a contract, to execute a function previously done in-house (Barret and Baldry, 2003). It refers to the act of procuring (some goods or services needed by a business or organization), under contract, with an outside supplier. Outsourcing is also considered as employing an outside agency to manage a function formerly carried on inside a company (Robertson and Rothery, 1995). There are many well-known advantages for the outsourcing practice. For example, the Outsourcing Institute, as reported by Troacă and Bodislav (2012), listed the top 10 reasons why a company would resort to outsourcing, namely: Cost reduction and operations control; Improving company focus; Gaining access to the various possibilities; Freeing internal resources for other purposes; Gaining resources are not available within the company; Accelerating the benefits of reengineering; Driving for some time is expensive; Employment equity; Sharing risks; and Capital injection.

\footnotetext{
${ }^{1}$ Assistant Prof., Civil Eng. Department, Taif University, KSA; E-mail: b.alsulami@tu.edu.sa, usama.issa@tu.edu.sa

${ }^{2}$ Assistant Prof., Civil Eng. Department, Taif University, KSA; E-mail: b.alsulami@tu.edu.sa, usama.issa@tu.edu.sa

${ }^{3}$ Professor, Griffith School of Engineering, Griffith University, Gold Coast campus, Queensland, Australia; Tel: +617-5552-8575; E-mail: s.mohamed@griffith.edu.au
} 
Engineering Consultancy in Construction Projects (ECCP) is considered critical outsourcing service. The engineering consultants play a greater role in construction project delivery. They are responsible for: developing the client's requirements; setting the targets and deadlines, and establishing standards for meeting these requirements; preparing project documents that describe targets, the deadlines and standards set; and, on many occasions, monitoring the contractors' progress to ensure that targets, deadlines and standards are achieved. Havemann (2007) explained, in detail, the consultants' role in the mitigation of the technical risks in a conventional project. The consultants are sourced from two areas: inhouse or external (Idoro, 2011; Boes and Doree, 2009).

In-house consultants can be described as internal service providers, or in-sourced consultants. They are professionals in the permanent employment of a client; they are engaged to perform the services of consultants in the procurement of a project. In contrast, outsourced consultants can be described as external or outsourced service providers. They are professionals who operate independently, and are engaged by a client to provide specialized services in the course of procuring a project (Idoro, 2011). The rest of this paper is organized as follows: Section 2 gives an overview of ECCP in the KSA public sector; Section 3 outlines the research methodology adopted; Section 4 briefly discusses factors governing ECCP in the KSA; Section 5 presents the current situation in the KSA ECCP; Section 6 discusses and presents the results; and, finally, Section 7 concludes the paper.

\section{ECCP in Public Sector in KSA}

The Saudi Arabian construction industry consists, basically, of the public and private sectors. Al-Sedairy (2001) states that: "The public sector pertains to the government ministries responsible for infrastructure and national development projects, while the private sector comprises construction firms privately owned or subsidized either by a family corporation or a conglomerate”. The main concern about consultants in the KSA public sector is that most of the major clients have departments in which the professionals are employed as the owner's representatives. Nevertheless, most of the engineering consultancy services, including design and/or supervision, are assigned to outsourced consultants.

Despite the large budget being spent on outsourcing consultant services, there is no scientific method or specific factors used in the evaluation of their performance. In the KSA, attention appears to be paid to technical problems, and not to improving the evaluation of CPPS. In the KSA public sector, the Saudi Government is the main promoter of construction projects and, therefore, it has much more power when negotiating with consultants. In the light of the above, the current research objectives involve: (1) identifying the main factors affecting outsourcing ECCP in the KSA; (2) defining which identified factors are used in the assessment of consultants' selection for CPPS either in an execution/supervision contract, or design contracts; and (3) evaluating the proposed factors to be used in selecting consultants.

\section{Research Methodology}

The methodology adopted in this research consisted of two phases. First, the research focused on acquiring the relevant knowledge through a literature review, as well as a series of semi-structured interviews regarding the outsourcing of decision factors. The objective of these interviews was to identify the main factors affecting ECCP selection, and to describe the current practice in light of the most commonly adopted contract types. The interviews also helped in identifying factors currently used in the evaluation of consultants in either supervision or design contracts. The interviews were followed by a questionnaire survey, the second phase, based on the knowledge available from the professionals in different public 
sectors in the KSA. The objective of the questionnaire was to collect data concerning whether or not the identified factors are currently being used in CPPS in the KSA. In addition, it measures the importance of using each factor in the evaluation of consultants in the CPPS.

\section{Factors Governing ECCP in KSA}

As explained earlier, in the first phase of the research methodology, the semi-structured interviews were conducted within a fairly open framework which allowed for conversational and two-way communication; in turn, this allowed for the giving and receiving of information. The main objective of these interviews was to identify the major factors that affect consultants' selections in the KSA and to describe the current situation, as well as to determine the factors' distribution within the consultants' contracts. Most of the interviewees represented the owners and public sectors.

Using previous research studies (such as Cheung et al. 2002, Chow and Thomas 2003, Thomas and Chow 2004a and b), a list of widely-reported factors was prepared. After the preliminary interviews were conducted the factors controlling the selection were identified, and are described briefly in Table 1. The table introduces a summary of the interviews for which the factors are currently used, even implicitly, in the current contracts. The table also summarizes the factors proposed for use in the execution/supervision or design contract.

As shown in Table 1, most of the identified factors were used in the consultant selection, but they are used randomly throughout the testing of the consultant engineers and their representatives. Most identified factors were suitable for use in consultants' evaluation in the execution contracts (29 from 30), while (24) factors were believed to be appropriate for the consultants' evaluation in the design contracts.

\section{Current situation in ECCP in KSA}

As stated before, most public sector contracts with the engineering consultants were either for the execution/supervision, design or supervision/design contracts. The consultants are often responsible for most pre-design services, and they are fully involved in both the design and construction activities. For public works projects carried out by both local and international contractors, the Saudi Arabian government uses, at all times, its own standard contract.

The following points were identified from the field survey and by exploring many contracts concerned with outsourcing KSA engineering consultants in CPPS:

1. Three familiar contracts are used in outsourcing consultants in CPPS in the KSA: execution/supervision, designs, and supervision/designs). The public sector determines which type is needed and the contract is prepared. Usually, the contract is sent to a limited number of consultants (5 to 7), for the purpose of selecting one for their respective submissions. Certain requirements are introduced in the tender and the consultant with lowest price is selected. Sometimes the selected consultants' staff are examined by the owner's representative to ensure that they have the collective capability to execute their allocated tasks. At other times the owner's representatives may ask the consultant to make staff changes, as they see fit. 
Table1. Identified factors the control outsourcing ECCP in KSA

\begin{tabular}{|c|c|c|c|c|c|}
\hline No. & Fcator & Currently & $\begin{array}{c}\text { Not } \\
\text { Currently }\end{array}$ & Supervision & Design \\
\hline & & used & Used & Contract & Contract \\
\hline 1 & Experience in Engineering Design & o & & o & o \\
\hline 2 & Experience in the supervising all execution works. & $\mathbf{o}$ & & $\mathbf{o}$ & \\
\hline 3 & Experience in supervising the maintenance works. & & $\mathbf{0}$ & $\mathbf{0}$ & \\
\hline 4 & Experience in the preparation of international and domestic contracts. & & $\mathbf{o}$ & $\mathbf{o}$ & $\mathbf{o}$ \\
\hline 5 & $\begin{array}{l}\text { Experience in quantitative risk analysis and quantification of cost and } \\
\text { time overruns. }\end{array}$ & & $\mathbf{o}$ & $\mathbf{o}$ & $\mathbf{o}$ \\
\hline 6 & Experience in risk management and risk allocation. & o & & $\mathbf{o}$ & o \\
\hline 7 & Familiarity with systems and laws in KSA. & $\mathbf{o}$ & & $\mathbf{0}$ & $\mathbf{o}$ \\
\hline 8 & Familiarity with Location of the project and knowledge of the area. & o & & $\mathbf{o}$ & $\mathbf{o}$ \\
\hline 9 & Experience in preparing all the contract and bid documents. & o & & & o \\
\hline 10 & Compliance with the National Codes of Practice. & $\mathbf{0}$ & & $\mathbf{o}$ & $\mathbf{o}$ \\
\hline 11 & Familiarity with all construction activities and methods of construction & $\mathbf{o}$ & & $\mathbf{o}$ & $\mathbf{o}$ \\
\hline 12 & Experience in managing project time. & $\mathbf{o}$ & & o & o \\
\hline 13 & Experience in the provision of project budget and reducing costs. & $\mathbf{o}$ & & $\mathbf{o}$ & $\mathbf{o}$ \\
\hline 14 & $\begin{array}{l}\text { Submission a full proposal for supervising plan, superior quality } \\
\text { achievement and occupational health safety. }\end{array}$ & $\mathbf{o}$ & & $\mathbf{o}$ & \\
\hline 15 & Experience in the management of change orders work. & $\mathbf{o}$ & & $\mathbf{o}$ & \\
\hline 16 & Experience in managing time-cost trade-off. & & $\mathbf{0}$ & o & o \\
\hline 17 & $\begin{array}{l}\text { Developing and using of decision-making models to support important } \\
\text { decisions. }\end{array}$ & & $\mathbf{o}$ & $\mathbf{o}$ & $\mathbf{0}$ \\
\hline 18 & Provide solutions to resolve disputes arising from contracts problems. & $\mathbf{o}$ & & $\mathbf{o}$ & $\mathbf{o}$ \\
\hline 19 & Provide a complete feasibility studies for the project. & $\mathbf{o}$ & & $\mathbf{o}$ & $\mathbf{o}$ \\
\hline 20 & Provide a scheduling dues payment for contractors and consultants. & & $\mathbf{0}$ & $\mathbf{o}$ & $\mathbf{o}$ \\
\hline 21 & $\begin{array}{l}\text { The presence of specialists such as civil, architectural, and electro- } \\
\text { mechanics and submit a proposal to remove the conflicts among them. }\end{array}$ & $\mathbf{o}$ & & $\mathbf{o}$ & $\mathbf{o}$ \\
\hline 22 & Experience in project monitoring and control & $\mathbf{o}$ & & $\mathbf{o}$ & $\mathbf{o}$ \\
\hline 23 & Determine the consulting stuff and their experiences for each project. & $\mathbf{0}$ & & $\mathbf{o}$ & $\mathbf{o}$ \\
\hline 24 & Experience in suppliers evaluation methods. & $\mathbf{0}$ & & $\mathbf{o}$ & \\
\hline 25 & Experience in project closes and full client's scope achievement. & $\mathbf{o}$ & & $\mathbf{o}$ & $\mathbf{0}$ \\
\hline 26 & The existence of an integrated organization structure. & $\mathbf{o}$ & & $\mathbf{o}$ & $\mathbf{o}$ \\
\hline 27 & The existence of an integrated quality control system. & $\mathbf{o}$ & & $\mathbf{o}$ & \\
\hline 28 & The existence of an integrated accounting. & $\mathbf{o}$ & & $\mathbf{o}$ & $\mathbf{0}$ \\
\hline 29 & Estimating productivity of manpower or equipments. & & $\mathbf{0}$ & $\mathbf{o}$ & $\mathbf{0}$ \\
\hline 30 & $\begin{array}{l}\text { Experience in new construction management techniques such as lean } \\
\text { construction. }\end{array}$ & & & $\mathbf{o}$ & $\mathbf{0}$ \\
\hline
\end{tabular}

2. In an execution/supervision contract, consultants are responsible for design works, including shop and as built drawings, and revising due to agreed-upon codes and specifications. Also they are responsible for revising all Bill of Quantities (BOQ), schedules, activities, any complementary drawings, and correcting and redesigning wrongs. They are expected to check the project scope achievement. In addition, they are responsible for previewing construction materials, following-up all material tests, and inspecting all equipment and control methods of implementation. Moreover, they are also expected to follow-up with monitoring safety systems at the site and site house-keeping and disposal of wastes. Other activities include preparing daily and monthly follow-up reports that concern works and the extent of progress and conditions of the contractor to identify the risk factors that hinder the work progresses now and in the future. The change orders need to be monitored and evaluated by the consultants, who also advise on any expected increase in time and cost estimates. 
3. In designs contract, the consultants are responsible for the most important requirements, including designing a detailed schedule for the design phase and documents. The contract includes an analysis study for the site and a contact with all the parties to obtain information concerning the project and to report any execution obstacles. The consultants must prepare an ideal design to suit the site and obtain an agreement from authorities. They also should conduct survey works, such as the establishment of fixed points, completing the leveling, and the survey work for the site, surrounding roads, and near substructures. Additionally, they must introduce a complete soil investigation through borings and laboratory tests, all of which are required for determining the soil properties. Besides the complete design for the project elements such as architectural, civil and electro-mechanics, they should introduce BOQ, specs and detailed schedule with expected obstacles. They are also required completing and getting required licenses and permits. Some requirements are introduced in the form of declarations.

\section{Field Survey and Data analysis}

Due to the lack of accessible organized information related to the method of outsourcing ECCP in the KSA, a questionnaire was designed using the proposed 30 factors (listed in Table 1). The list was used to determine which factors were currently used in the evaluation of the consultants, as well as to define the importance and weight of each factor in evaluating the consultants' selection process. The approach using the questionnaire is well-recognized and widely used in general management and project management research (e.g. ASCE Construction Survey 1979, Bing et al. 1999, Shen et al. 2001, Thomas et al. 2003).

A direct (face-to-face) delivery of most questionnaires was used to motivate the respondents, and to ensure the accuracy of the answers and to improve the response rate, as stated by Long et al. (2004). Another online questionnaire format was prepared and sent to many respondents. The designed questionnaires were directed towards the three partners in the construction industry groups: the owners and their representatives, the consultant engineers, and the contractors. The questionnaire was divided into two sections; the first section was to learn the general particulars of the respondents, while the second section was to focus on the factors. The respondents were asked to choose one of five levels for the importance of each factor. These levels ranged from being very important to not important. More details will be explained later about these levels, and how they were selected for the questionnaires to suit the proposed importance index, as used in the factors assessment.

\section{Summary of the questionnaire outputs}

One hundred and twenty-two (122) questionnaires were distributed (both hard copies and on line forms) throughout the KSA. The total number of respondents participating in and completing the survey was 66 . As for the total sample, 29 out of 60 questionnaires were received from the owners, 20 out of 32 from the consultants, and 17 out of 30 copies were received from the contractors, as shown in Table 2. The response rates from the different groups were owners- $48.33 \%$, consultants-62.50 \%, and contractors $-56.67 \%$, with an average response rate of $54 \%$. The owners had the highest frequency at $44 \%$, followed by the consultants at $30 \%$, and then the contractors at $26 \%$. The researchers deemed to concentration the distribution, about $50 \%$ of the questionnaires, to the owner representatives as they are the most influential in the decision-making process for outsourcing ECCPs. 
Table 2. Questionnaire Returns Rate and Frequency of Participation

\begin{tabular}{ccccc}
\hline Respondents & Owners & Consultants & Contractors & Total \\
\hline Questionnaire distributed & 60 & 32 & 30 & 122 \\
Responses received & 29 & 20 & 17 & 66 \\
Response rate (\%) & $48.33 \%$ & $62.50 \%$ & $56.67 \%$ & $54 \%$ \\
Frequency of participation & $44 \%$ & $30 \%$ & $26 \%$ & $100 \%$ \\
\hline
\end{tabular}

\section{Respondents' experience}

The strength of the respondents' experience indicates the degree of reliability of the data provided by them. About $28.78 \%$ of the professionals who participated in the survey had over 20 years' experience which, in turn, raises the reliability of the data collected from the shared knowledge of long years of experience in the CPPS in the KSA. Also, to ensure that the survey results were credible, any replies from respondents with less than five years of experience were discarded. As shown in Table 3, $27.27 \%$ of the participants had 15 to 20 years' experience. The frequency of the respondents who had 10 to 15 years' experience was $24.25 \%$, whereas the remaining respondents (19.70\%) had 5 to 10 years relevant experience. The average working experience of all respondents was 16.47 years in CPPS in the KSA; thus, their opinions are thought to reflect the current and real situation in the industry.

Table 3. Years of Experience for the Respondents

\begin{tabular}{cccccc}
\hline Years of experience & $5-10$ years & $\begin{array}{c}10-15 \\
\text { years }\end{array}$ & $\begin{array}{c}15-20 \\
\text { years }\end{array}$ & $\begin{array}{c}>20 \\
\text { years }\end{array}$ & Total \\
\hline No of respondents & 13 & 16 & 18 & 19 & 66 \\
Percent from sample & $19.70 \%$ & $24.25 \%$ & $27.27 \%$ & $28.78 \%$ & $100.0 \%$ \\
\hline
\end{tabular}

\section{Relative Importance Index (RII)}

The analysis for all the identified factors was conducted to determine the relative weight for each factor used in consultants' selection evaluation. The contribution of each of the importance factors of use in the consultants' selection was examined, while the ranking of the attributes, in terms of their criticality as perceived by the respondents, was achieved by the use of the Relative Importance Index (RII). The RII was determined for the three partner groups (owners, consultants, and contractors). The collected data from this section of the questionnaire concerns the identified factors in the five level format (very important, important, medium important, low important, and not important). Equation (1) was used to calculate the RII for all the factors. The weights were ranked for the owners, consultants, and contractors. The results of the analysis are presented in Table 4 . The rankings for all the factors, due to their RII values, were determined from the average of all the respondents. In the next sections, the proof for using the average will be introduced. 


$$
R I I=\frac{\sum_{i=1}^{5} R i * N i}{\sum_{i=1}^{5} N i}
$$

Equation (1)

\section{Where:}

$R I I$ is the relative importance index for a certain identified factor;

$R i$ is the importance weight, and equal to $0.9,0.7,0.5,0.3$, and 0.1 for $\mathrm{i}=5,4,3,2$, and 1 , respectively;

$\mathrm{Ni}$ is the number of participants who responded to option $i$

$i=1,2,3,4,5$;

$\mathrm{Ni}$ is a factor expressing the frequency of the ith response (ranging between N1=frequency of the 'not important' response, and $N 5=$ frequency of the 'very important' response)

\section{Results, Discussion and Analysis}

\section{Agreement Analysis}

It is not practical here to separate the analysis of the results for each of the three participant groups (the owners and their representatives, the consultants, and the contractors); therefore, it is displayed as a summary of the findings. The Spearman's Rank Correlation Coefficient test was used to check the level of agreement amongst the respondent groups for the ranking of the factors.

The Spearman's Rank Correlation Coefficient is a non-parametric measure of correlation and is used to discover the strength of a link between two sets of data. Altman (1991), and Finkelstein and Levin (2000) described the Spearman rank-order correlation coefficient as a measure of the linear relationship between two sets of ranked data; it measures how tightly the ranked data clusters around a straight line.

The Spearman test was applied to the three pairs of groups to ensure a strong agreement about the ranking, based on the RII for all the factors. Due to the different pairs of groups, the Spearman's correlation coefficients for the ranking factors are determined and presented in Table 5. The coefficient value from the RII values between the consultants and the owners is somewhat high value (0.680), while the coefficient value between the contractors and the consultants was the lower value (0.410). The highest agreement was between the owners and the contractors, with a coefficient value of 0.899 . This result reflects the great agreement between the owners and the contractors related to identifying the factors related to assessing the consultants because not all these factors affect them, and only affect the third party.

On the other hand, the consultants try to mitigate the conditions and requirements for selection. That occurs where all the results are positive, which implies a good agreement among the different groups. Thus, it can be concluded that there is a high degree of agreement among the three groups on the level RII. Therefore, a further attempt to analyze the problems faced by the different groups of respondents is not necessary; hence, a full analysis and evaluation of the factors can be introduced, based on the outcome of the average of all the respondents, as determined in Table 4.

Table 4. The determined RII values for all identified factors 


\begin{tabular}{|c|c|c|c|c|c|c|}
\hline \multirow{2}{*}{ No. } & \multirow{2}{*}{ Fcator } & \multicolumn{4}{|c|}{ RII due to } & \multirow{2}{*}{ Rank } \\
\hline & & Owners & Consultants & Contractors & Average & \\
\hline 1 & Experience in Engineering Design & 0.77 & 0.76 & 0.81 & 0.78 & 1 \\
\hline 19 & Provide a complete feasibility studies for the project. & 0.77 & 0.68 & 0.77 & 0.74 & 2 \\
\hline 2 & Experience in the supervising all execution works. & 0.74 & 0.70 & 0.72 & 0.72 & 3 \\
\hline 7 & Familiarity with systems and laws in KSA. & 0.73 & 0.64 & 0.76 & 0.71 & 4 \\
\hline 10 & Compliance with the National Codes of Practice. & 0.73 & 0.65 & 0.75 & 0.71 & 5 \\
\hline 14 & $\begin{array}{l}\text { Submission a full proposal for supervising plan, superior quality } \\
\text { achievement and occupational health safety. }\end{array}$ & 0.73 & 0.65 & 0.74 & 0.71 & 6 \\
\hline 23 & Determine the consulting stuff and their experiences for each project. & 0.71 & 0.65 & 0.71 & 0.69 & 7 \\
\hline 15 & Experience in the management of change orders work. & 0.71 & 0.64 & 0.71 & 0.69 & 8 \\
\hline 21 & $\begin{array}{l}\text { The presence of specialists such as civil, architectural, and electro-mechanics } \\
\text { and submit a proposal to remove the conflicts among them. }\end{array}$ & 0.71 & 0.66 & 0.69 & 0.69 & 9 \\
\hline 11 & Familiarity with all construction activities and methods of construction & 0.71 & 0.62 & 0.74 & 0.69 & 10 \\
\hline 20 & Provide a scheduling dues payment for contractors and consultants. & 0.71 & 0.62 & 0.74 & 0.69 & 11 \\
\hline 26 & The existence of an integrated organization structure. & 0.70 & 0.65 & 0.69 & 0.68 & 12 \\
\hline 27 & The existence of an integrated quality control system. & 0.70 & 0.62 & 0.72 & 0.68 & 13 \\
\hline 22 & Experience in project monitoring and control. & 0.69 & 0.62 & 0.71 & 0.68 & 14 \\
\hline 8 & Familiarity with Location of the project and knowledge of the area. & 0.69 & 0.61 & 0.72 & 0.67 & 15 \\
\hline 24 & Experience in suppliers evaluation methods. & 0.69 & 0.62 & 0.70 & 0.67 & 16 \\
\hline 13 & Experience in the provision of project budget and reducing costs. & 0.69 & 0.60 & 0.72 & 0.67 & 17 \\
\hline 25 & Experience in project closes and full client's scope achievement. & 0.68 & 0.61 & 0.70 & 0.66 & 18 \\
\hline 29 & Estimating productivity of manpower or equipments. & 0.68 & 0.61 & 0.70 & 0.66 & 19 \\
\hline 5 & $\begin{array}{l}\text { Experience in quantitative risk analysis and quantification of cost and time } \\
\text { overruns. }\end{array}$ & 0.67 & 0.61 & 0.69 & 0.66 & 20 \\
\hline 9 & Experience in preparing all the contract and bid documents. & 0.67 & 0.61 & 0.69 & 0.66 & 21 \\
\hline 12 & Experience in managing project time. & 0.67 & 0.60 & 0.70 & 0.66 & 22 \\
\hline 17 & Developing and using of decision-making models to support important decisions. & 0.67 & 0.62 & 0.66 & 0.65 & 23 \\
\hline 6 & Experience in risk management and risk allocation. & 0.67 & 0.62 & 0.66 & 0.65 & 24 \\
\hline 28 & The existence of an integrated accounting. & 0.65 & 0.60 & 0.66 & 0.64 & 25 \\
\hline 16 & Experience in managing time-cost trade-off. & 0.64 & 0.61 & 0.64 & 0.63 & 26 \\
\hline 3 & Experience in supervising the maintenance works. & 0.64 & 0.64 & 0.61 & 0.63 & 27 \\
\hline 4 & Experience in the preparation of international and domestic contracts. & 0.63 & 0.61 & 0.63 & 0.62 & 28 \\
\hline 18 & Provide solutions to resolve disputes arising from contracts problems. & 0.62 & 0.62 & 0.59 & 0.62 & 29 \\
\hline 30 & $\begin{array}{l}\text { Experience in new construction management techniques such as lean } \\
\text { construction. }\end{array}$ & 0.62 & 0.61 & 0.61 & 0.62 & 30 \\
\hline
\end{tabular}

Table 5. Spearman's correlation coefficients for ranking factors due to different pairs of groups

\begin{tabular}{lc}
\hline \multicolumn{1}{c}{ Group } & Spearman's coefficients \\
\hline Consultants and owners & 0.680 \\
Contractors and consultants & 0.410 \\
Owners and Contractors & 0.899 \\
\hline
\end{tabular}

\section{Ranking analysis}

The ranking analysis is based on the agreement among the three groups; the analysis of the ranking factors is presented in relation to the total number of respondents (see Table 1). From these rankings, many factors were observed to have a high rank, such as factors 1 , 19, and 2, which was expressed as the "Experience in Engineering Design"; "Provide complete feasibility studies for the project"; and "Experience in the supervising of all execution works", respectively. On the other hand, factors 4, 18, and 30, which are "Experience in the preparation of international and domestic contracts"; "Provide solutions to resolve disputes arising from contracts problems"; and "Experience in new construction management 
techniques, such as lean construction", respectively. They appear, in spite of their importance, in the bottom of the list due to their low RII values. In all cases, the difference does not exceed $25 \%$. This small value indicates that all factors should be taken into considerations.

\section{Boxplot Analysis}

The boxplot (or box-and-whisker-plot), invented by John Tukey in 1977, is an efficient way to the present data. It can provide a quick visual summary that easily shows the centre, spread, range, and any outliers. The box contains $50 \%$ of the data, the upper edge of the box represents the 75th percentile, the lower edge represents the 25th percentile, and the median is represented by a line drawn in the middle of the box. The ends of the lines (called whiskers) represent the minimum and maximum values of the data set, unless the data contain outliers. The outliers are observations below Q1 - 1.5(IQR) or above Q3 + 1.5(IQR), where Q1 is the 25th percentile, Q3 is the 75th percentile, and IQR = Q3 - Q1 (called the interquartile range). The outliers are labeled on the graph with a small circle above or below the range.

In this research, a boxplot analysis is introduced to summarise and compare the sets of data for the RII values of factors in the cases of the owners, the consultants, the contractors, and the average of all respondents. The boxplot was drawn for the RII values and was constructed side-by-side for all the mentioned cases. These plots are presented in Figure 1. Notably, the range is the widest for the cases of the contractors. This wide range for RII values refers to the large differences among the RII values, from the point of view of the contractors, where the RII ranges from 0.805 to 0.59 . This case includes the highest RII value for factor 1, "Experience in Engineering Design". The ranges in the boxes for the other cases (the consultants, the owners, and the average) are closer, which indicates that the factors have closer RII values. Factor No. 1 is an outlier in the case of the consultants and the average. This finding proves that the factor is very important for selecting the consultants compared to other factors. Most consultants prefer to give this factor more importance than others because they have good skills in design rather than in the other factors. With the exception of that factor, No. 1 is an outlier; the drawing of boxplot in the case of the average seems to be the ideal. This result confirms the use of the average RII values in these findings.

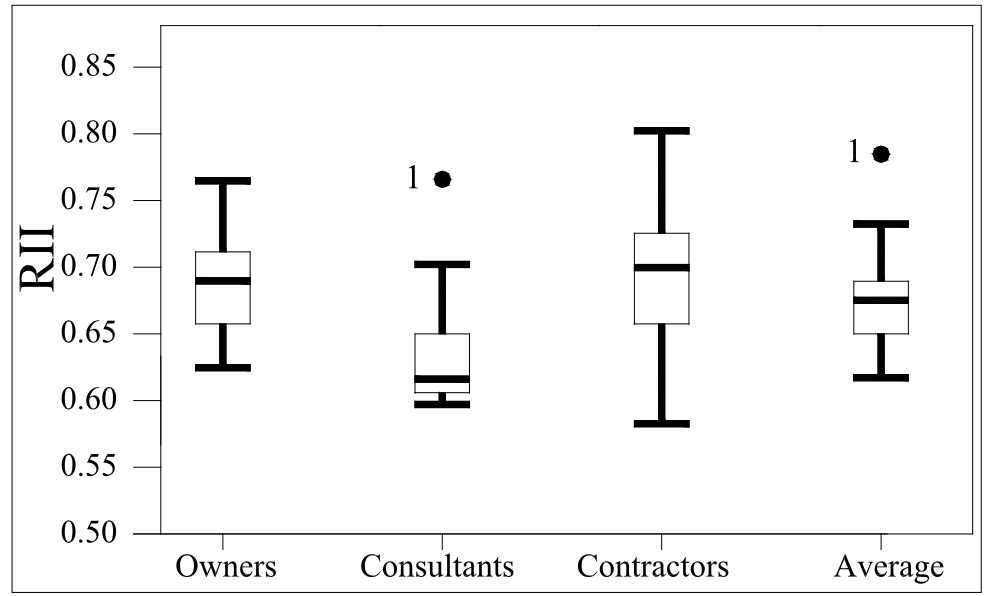

Figure 1. Boxplot analysis for RII values selected by all respondents 


\section{Conclusions}

Due to the increase in the number of CPPS in the KSA, in recent years, the trend to outsource engineering services, such as engineering consultancies, have continued to increase. The consultants' selection for such projects is not subject to scientific methods or models; hence, this research aims to evaluate the current selection criteria and to assess it. In addition, it introduces a relative importance for each identified factor which can be used in the selection process, and as a foundation for building a mathematical decision support model for consultant selections. With the assistance of a practical survey, this research identified and assessed thirty factors affecting ECCP in the KSA. The identified factors were evaluated using the RII, providing an effective insight into, and a clear picture of the factors' importance. RII represents the importance of each factor for evaluating and selecting the consultants. The Spearman's rank correlation coefficient was used to test the strength of the associations between the rankings of the respondent groups. Based on the obtained results, seven specific conclusions can be drawn as follows:

1. Three common contracts in outsourcing ECCP in the KSA are execution/supervision, design, and design/supervision contracts. The results identified 29 factors used in evaluating the execution/supervision contract, while 24 factors were used in evaluating the design contract.

2. At present, many identified factors may be used in outsourcing ECCP in the KSA, indirectly and not officially, without regulations in the consultants' selection.

3. The analysis of the field survey shows that respondents' are characterized by high experiences. About half of the respondents are represented by the owners, because they are the main decision makers related to the job.

4. The agreement analysis amongst the three partners using the Spearman test shows that there is a good agreement amongst them, while the highest agreement is between the owners and the contractors. This high agreement is an expected result because these requirements concern the third party. The consultants try to mitigate the conditions and the requirements for selection.

5. The box plot analysis confirms using the average respondents' results for the RII, as well as the agreement test. The "Experience in Engineering Design" factor is located as an outlier in the cases of the consultants and the average with a high value, rather than the other factors. This factor is very important for selecting the consultants compared to other factors. Most consultants prefer to give this factor more importance than others because they have high skills in design rather than in the other factors.

6. The results showed that all the identified factors should be taken into consideration by the owners in evaluating and selecting the consultants.

7. The results introduced, for each contract type, a group of factors and their relative weights through the RII. This indicator is a new reference for the factors assessment introduced in this research. It can be used for weighing the factors when evaluating and selecting the consultants in the public sector tenders in the KSA. 


\section{References}

Al-Sedairy, S., 2001. A change management model for Saudi construction industry. International Journal of Project Management. 19(3), 161-169.

Altman, D.G. 1991. Practical statistics for medical research. Chapman \& Hall, London.

ASCE., 1979. Construction Survey. Proceedings of conference on construction risks and liability sharing, ASCE, 1, New York.

Bannan, A., Elmualim, A. and Tang, L., 2012. Benchmarking and key performance indicators for the construction industry in Saudi Arabia. Proceeding of International Conference on facilities management, procurement systems and public private partnership. Cape Town, South Africa.

Barrett, P., and Baldry, D. 2003., Facilities Management: Towards Best Practice. Blackwell Science Ltd, UK.

Bing, L., Tiong, L. K., Fan, W. W. and Chew, D. A., 1999. Risk management in international construction joint ventures. Journal of Construction Engineering and Management, 125(4), 277-284.

Boes, H. and Doree, A., 2009. Public procurement of local authorities in the Netherlands: a case of breaking tradition for a more strategic approach. Proceedings of RICS COBRA Research Conference, University of Cape Town, 10-11 ${ }^{\text {th }}$ September.

Cheung, F.K.T., Kuen, J. L.F. and Skitmore, R.M., 2002. Multicriteria Evaluation Model for Selection of Architectural Consultants. Construction Management and Economics, 20(7), 569-580.

Chow, L. and Thomas, N., 2003. Performance-based evaluation for engineering consultants: a study of assessment criteria. 19th Annual ARCOM Conference, Association of Researchers in Construction Management, Vol. 1, 433-42.

Finkelstein, M. O. and Levin, B., 2000. Statistics for Social Science and Public Policy. Springer, New York.

Havemann, G., 2007. The challenge of engaging South Africa's unemployed in construction sector delivery', Proceeding of the CIB World Building Conference on Construction for Development, Cape Town, South Africa, 14-18 May 2007.

Idoro, G. I., 2009. Clients' perception of construction project leaders in the Nigerian construction Industry. Journal of Engineering, Design and Technology. 7 (3), 264-271.

Idoro, G. I., 2011. Influence in-sourcing and outsourcing of consultants on construction project performance in Nigeria', Australasian Journal of Construction Economics and Building, 11 (4), 45-58

Long, N. D., Ogunlana , S. Quang, T. and Lam, K. C., 2004. Large construction projects in developing countries: a case study from Vietnam. International Journal of Project Management, 22(7), 553-561.

Robertson, I. and Rothery, B., 1995. The Truth about Outsourcing. Gower Publishing Limited.

Shen, L. Y., George W. C. and Catherine S. K., 2001. Risk assessment for construction joint ventures in China. Journal of Construction Engineering and Management, 127(1), 7681.

Thomas, A. V., Kalidindi, S.N. and Ananthanarayanan, K., 2003. Risk perception analysis of BOT road project participants in India. Journal of Construction Management and Economics, 21(4), 393-407.

Thomas, N. and Chow, L., 2004a. Evaluating engineering consultants' general capabilities during the pre-selection process - a Hong Kong study. Engineering, Construction and Architectural Management, 11(3), 150-158 
Thomas, N. and Chow, L., 2004b. Framework for Evaluating the Performance of Engineering Consultants. Journal of Professional Issues in Engineering Education and Practice, 130(4), 280-288.

Troacă, V and Bodislav, D., 2012. Outsourcing. The Concept. Theoretical and Applied Economics. XIX (6), 51-58.

Tukey, J. W. 1977. Exploratory Data Analysis. Addison-Wesley, Reading, Mass.

\section{Acknowledgements}

Funding of this study is provided through a research project grant from Taif University, KSA. The authors appreciate the financial support of this respected organization. Special thanks to all engineers who participated in the interviews, or completed the questionnaires, as well as for their help and support during this work. 